\title{
MIGRASI ORANG BUGIS DI BENGKULU DALAM PERSPEKTIF SEJARAH
}

\author{
Agus Setiyanto \\ Fakultas Ilmu Sosial dan Politik Universitas Bengkulu \\ Jl. Wr. Supratman, Kandang Limun Bengkulu \\ agussetiyantoz@yahoo.com
}

\begin{abstract}
The background of the migration of the Bugis people is inseparable from the socio-cultural system that has been tradition in the lives of the people. One of the socio-cultural systems that has been embedded in the life view of the Bugis community is very strong, namely the so-called 'siri'. The Bugis recognize two types of siri, namely siri ripakasiri, and sirimasiri. The initial process of migration The large family of indigenous Bugis to Bengkulu in the seventeenth century, actually can not be separated from the role of the Indrapura kingdom as the gate way (entrance) of various tribes that came from the north towards the Benkoelen region (Bengkulu).
\end{abstract}

Keywords: Bugis people, migration, Bengkulu

Abstrak: Latar belakang migrasinya orang-orang Bugis sebenarnya tidak terlepas dari sistem sosial budaya yang telah mentradisi dalam kehidupan masyarakatnya. Salah satu sistem sosial budaya yang telah terpatri dalam pandangan hidup masyarakat Bugis yang sangat kuat, yaitu yang disebut 'siri'. Orang Bugis mengenal dua macam siri, yaitu siri ripakasiri, dan sirimasiri. Proses awal migrasinya Keluarga besar pribumi Bugis ke Bengkulu pada abad XVII, sebenarnya tidak lepas dari dari peranan kerajaan Indrapura sebagai gate way (pintu masuk) nya berbagai suku-bangsa yang datang dari arah utara menuju wilayah Benkoelen (Bengkulu).

Kata Kunci: Orang Bugis, migrasi, Bengkulu

\section{A. PENDAHULUAN}

Latar belakang migrasinya orangorang Bugis sebenarnya tidak terlepas dari sistem sosial budaya yang telah mentradisi dalam kehidupan masyarakatnya. Salah satu sistem sosial budaya yang telah terpatri dalam pandangan hidup masyarakat Bugis yang sangat kuat, yaitu yang disebut 'siri'. Orang Bugis mengenal dua macam siri, yaitu siri ripakasiri, dan sirimasiri. ${ }^{1}$

Menurut salah satu sumber, jiwa petualangan orang-orang Bugis sudah berlangsung sejak abad ke 16.2 Bahkan dalam historiografi tradisional yang dikenal dengan nama I La galigo ( cerita mengenai Bugis kuno) yang berhasil dikumpulkan oleh Kern, jiwa berpetualang orang Bugis itu sudah dilakukan sejak zaman Sawerigading. ${ }^{3}$

Mengenai proses awal migrasinya orang Bugis ke Bengkulu hingga sampai ke Indrapura juga banyak diungkap melalui hasil catatan O.L. Helfrich maupun tulisannya Winter yang berhasil melacak keluarga keturunan Bugis melalui Babad Melayu.

Proses awal migrasinya Keluarga besar pribumi Bugis ke Bengkulu pada abad XVII, sebenarnya tidak lepas dari dari peranan kerajaan Indrapura sebagai gate way (pintu masuk) nya berbagai suku-bangsa yang datang dari arah utara menuju wilayah Benkoelen (Bengkulu). Oleh sebab itu, perlu dijelaskan terlebih dahulu mengenai proses migrasinya Keluarga besar pribumi keturunan Bugis ini dari Indrapura hingga ke Bengkulu.

\section{Dari Tanah Wajo Menuju Indrapura.}

Petualangan orang Bugis sampai ke kerajaan Indrapura, berdasarkan sebuah sumber tradisional yang disebut 
Maleisch-handschrift (Babad Melayu) yang berhasil dihimpun oleh Winter pada tahun 1874, diketahui sebagai berikut:

In het door Boegineezen bewoonde gedeelte van Celebes, in het district Toeadjo, voerde de vorst van het dorp Benteng oorlog met den vorst van Tasoero, eveneens in het district Toeadjo, en hoezeer de strijd geruimen tij geduur had, kon hij Tasoero niet overwinnen.

Hij had een jongeren broeder, Daing Maroepa, ook hoofd in het dorp, een stoutmoedig man. Deze stelde voor, om Tasoero met een krijgsbende te overvallen en op dood en leven te kampen; maar de vorst van Benteng wilde hiertoe zijn toestemming niet geven. Daardoor gebelgd, verliet Daing Maroepa Benteng met zijn vrouw en gezin, en stak in een vaartuig naar Java over, met het voornemen zich daar te vestigen. Op zee veranderde bij van voornemen en wendde den steven naar Benkoelen. In de nabijheid van deze plaats werd hij door een hevigen storm overvallen en naar Indrapoera afgedreven, ... ${ }^{4}$

Berdasar sumber di atas, dapat dijelaskan bahwa di wilayah Sulawesi yang dihuni oleh suku Bugis, di distrik Toeadjo (Wajo), terjadi peperangan antara penguasa desa Benteng dengan raja Tasuro yang berlangsung lama. Oleh karena tak dapat mengalahkan raja Tasuro, saudara mudanya penguasa desa Benteng yang bernama Daeng Marupa (Daing Maroepa) yang juga sebagai kepala desa yang terkenal dan pemberani itu mengusulkan menyerangnya lagi dengan pasukan tempur untuk menangkap Raja Tasoero hidup atau mati.

Usul Daing Marupa itu ternyata tidak direspon oleh saudara tuanya. Oleh karena merasa kecewa, Daing Marupa bersama istri dan keluarganya meninggalkan desa Benteng, pergi berlayar menuju ke Jawa untuk menetap di sana. Di tengah laut, tujuannya berubah, dan mengarahkan perhatiannya ke Benkoelen. Akan tetapi ternyata dilanda badai hebat sehingga terdampar di wilayah Indrapura.

Tekad dan semangat Daing Marupa untuk berlayar mengarungi lautan, meninggalkan tanah leluhurnya, merupakan bagian dari salah satu semboyan bagi para pelaut Bugis yaitu :

Pura ba 'bara' sompeku

Pura 'tangkisi' gulikku

Ule' birengngi telleng natoalie'

Artinya:

Layarku telah kukembangkan

Kemudiku telah kupasang

Kupilih tenggelam daripada surut. ${ }^{5}$

Apabila dikaitkan dengan kosep "siri", motivasi Daing Marupa sekeluarga meninggalkan tanah asalnya lebih didasari oleh semangat siri' ripakasiri, karena perasaan kecewa itu datangnya dari luar dirinya. Menurut Andi Zainal Abidin, siri' ripakasiri' merupakan faktor eksternal, yaitu apabila harkat dan martabatnya dihina atau dilanggar oleh orang lain, maka orang Bugis cenderung mempertahankannya. Untuk mengembalikan siri' tersebut, maka bermigrasi (berpetualang) merupakan jalan terbaik. ${ }^{6}$

Menurut catatan O.L. Helfrich, Daing Marupa yang juga bernama Lampu Lana ini, dalam pelayarannya, perahunya mengalami rusak berat, bahkan pengikutnya banyak yang tenggelam di tengah lautan hingga perahunya kandas di wilayah Indrapura. Akibatnya, perahu dan segala isinya dirampas, bahkan Daing Marupa dan manschappen (anak-buah) nya ditangkap dan dibawa kepada Tuanku Sultan Indrapura.

Setelah Daing Marupa menceritakan asal-usul dan kejadiannya, Tuanku Sultan kemudian mengembalikan barang-barang yang telah dirampas, 
dan memberikan tempat perlindungan di istananya. Alasan Sultan Indrapura memberikan perlindungan kepada Daing Marupa dan anak buahnya, dapat dijelaskan sebagai berikut :

Indrapoera had n.l zijn onstaan ten danken aan Boegineesche handelaren, die zich aldaar gevestigd hadden. Tot vorst van Indrapoera werd toen een Boeginees gekozen, die met een adelijk meisje, afkomstig van het machtig rijk van Pagaroejoeng, huwde. ${ }^{7}$

Berdasarkan catatan tersebut di atas, dapat dijelaskan, bahwa kerajaan Indrapura itu bisa berdiri karena jasa para pedagang Bugis yang ada di wilayah Indrapura. Bahkan pernah ada seorang Bugis yang menjadi raja di Indrapura dan menikah dengan seorang gadis keturunan bangsawan dari kerajaan Pagaruyung.

Dengan demikian, cukup jelas bahwa ternyata Daing Marupa bukan orang yang pertama kali datang ke Indrapura, karena jauh sebelumnya sudah ada para pedagang Bugis yang menetap di wilayah Indrapura. Oleh karena cukup lama menetapnya, maka wajarlah bila kemudian menjalin hubungan kekerabatan melalui sistem perkawinan. Bahkan setelah suskses bisa menjadi orang terhormat (jadi raja) di wilayah tersebut.

Selanjutnya dalam catatan Helfrich, petualangan Daing Marupa dikisahkan sebagai berikut:

Nadat Daing Maroepa reeds geruimen tijd aan het hof van den Toewankoe van Indrapoera was verbonden, was de Vorst zeer begaan met hem. Hij riep daarom al zijn mantris en verwanten bijeen, won hun advies in omtrent zijn voornemen om Daeng Maroepa als kind aan te nemen door hem met's Vorsten zuster te doen huwen. De geheele vergadering juichte dit plan toe en zoo geschiedde het. Uit dat huwelijk ontsproot nu, zooals reeds vermeld is. Soelthan Selan gelar Daing Mabela. 8
Melalui catatan di atas, dapat diketahui bahwa setelah Daing Marupa tinggal cukup lama di istana, Tuanku Indrapura pun sangat simpati kepadanya. Dalam sidang kerapatan para mantri dan pembesar kerajaan, telah diusulkan untuk mengadopsi Daing Marupa sebagai anak raja, serta dikawinkan dengan adik perempuan Sultan. Dari hasil perkawinan tersebut, maka lahirlah Sultan Selan yang bergelar Daing Mabela.

Menurut beberapa sumber, ${ }^{9}$ nama lain dari Daing Mabela adalah Si Unus. Kemungkinan besar, Si Unus adalah nama kecilnya, sedangkan Daing Mabela adalah gelar Bugisnya. Oleh karena Daing Mabela kemudian diangkat menjadi raja di Indrapura, maka diberinya gelar Sultan Selan, atau Sutan Balinam menurut Naskah Melayu.

berikut :

Selanjutnya dikisahkan sebagai

Toen Daing Mabela een jongeling werd, kreeg zijn vader een brief uit Wadjo, waarin de Vorst Lasakati Pata Maplahe hem uitnoodigde terug te keeren. Daing Maroepa verlangde zeer naar zijn verwanten en zijn land. Nadat de Vorst van Indrapoera hem vergunning gaf om te vertrekken, onder voorwaarde echter spoedig terug te keeren, zielde Daing Maroepa naar zijn vaderland, vrouw en kind achterlatende. Niet lang daarna stierf de oude Toewankoe van Indrapoera en zijn zoon zoude hem moeten vervangen, maar aangezien deze met daing Mabela samen was opgegroeid, besloot men, dat de waardigheid van Toewankoe door beide zoude bekleed worden. Het verhaal wil nu, dat onder de regeering van deze beide Vorst Indrapoera een ongekenden bloei genoot en dat hun eerlijkheid en wijsheid alom geprezen werden. ${ }^{10}$ 
Berdasarkan catatan di atas, dapat dijelaskan, bahwa ketika Daing Mabela sudah menginjak dewasa, ayahnya (Daing Marupa) menerima surat dari kakandanya raja Wajo yang bernama Lasakati Petta Maplahe, yang mengharapkan agar Daing Marupa segera pulang kembali. Daing Marupa snagat ingin pulang menjumpai saudara dan kampung halamannya. Raja Indrapura lalu mengizinkan pergi berlayar menuju kampung halamannya, dengan syarat tidak disertai anak dan istrinya, dengan maksud agar Daing Marupa segera kembali lagi. Akan tetapi, tak lama kemudian, Tuanku Indrapura yang sudah tua itupun meninggal dunia. Dan anaknya laki-laki yang tertualah yang harus menggantikannya. Akan tetapi karena anaknya laki-laki tertua itu telah tumbuh menjadi besar bersama dengan Daing Mabela, maka diputuskan bahwa, keduanya menduduki jabatan sebagai Tuanku.

Selanjutnya diceritakan, bahwa kerajaan Indrapura di bawah pemerintahan kedua raja ini, telah berkembang pesat, kejujuran dan kebijaksanaan telah terpuji di seluruh penjuru wilayahnya.

Kepulangan Daing Marupa ke kampung halamannya (Wajo), menunjukkan bukti, bahwa orang Bugis akan menampakkan dirinya kembali ke tanah asalnya setelah sukses di tanah rantau. Dan kembalinya daing Marupa dapat dianggap sebagai tanda kembalinya siri'nya.11Keberhasilan Daing Mabela sebagai orang besar di wilayah Indrapura jelas membawa pengaruh yang cukup besar bagi keluarga besar Bugis.

\section{Migrasi ke Bengkulu}

Secara historis awal migrasinya orang-orang Bugis ke Bengkulu berkaitan dengan kebijakan The Right Honourable English East India Company yang telah bercokol di Bengkulu sejak tahun 1685.12

Menurut laporan Sumatra Factory Record 2, 9 Jan 1688, pada awal tahun 1688, pemerintah kompeni Inggris bermaksud mengundang Orumkey Lilla (Orangkaya Lela) dari Indrapura, untuk membantu keamanan di wilayah Bengkulu. Akan tetapi ternyata yang datang adalah Daing Marupa bersamasama dengan para saudagar Bugis dan pasukan Ambon. ${ }^{13}$ Besar kemungkinan, Orangkaya Lela tidak bersedia datang ke Bengkulu karena pernah terlibat kasus hutang dengan pihak kompeni Inggris tahun 1685. Berdasarkan isi surat dari pihak pimpinan kompeni Inggris di bawah Benyamin Bloome pada bulan Januari 1686 kepada Karia Suttra Gistra (utusan Sultan Banten), disebutkan bahwa hutang Orangkaya Lela tercatat sebesar 4.000 dollar. ${ }^{14}$

Sejak tahun 1686 itulah keluarga Bugis di bawah pimpinan Daing Marupa mulai berpengaruh di wilayah Bengkulu sebagai pasukan keamanan di bawah koordinasi kompeni Inggris. Dua tahun kemudian (1688) anak keturunan Daing Marupa, yaitu Sutan Endey (saudara Daing Mabela) diangkat oleh pemerintah Inggris sebagai Chief Captain (Kapten Kepala), yang tergabung dalam kesatuan khusus Bugis (Bugis Corps). Korps militer Bugis ini diberi tugas khusus untuk membantu meredam perang saudara di wilayah Anak Sungai. ${ }^{15}$ Menurut sebuah sumber, wilayah Anak Sungai, adalah wilayah Bengkulu paling Utara, antara Manjuto dan Ketaun, yang terdiri atas Muko-Muko, Bantal, Seblat, dan Ketaun. ${ }^{16}$

Dalam perkembangan selanjutnya, diberitakan bahwa pada tahun 1695, hubungan antara Sutan Endey dengan pihak kompeni Inggris telah putus, gara- 
gara pihak kompeni Inggris tidak bersedia menyertakan Sutan endey dalam hal monopoli perdagangan mrica di wilayah Bengkulu. Akibatnya, pihak kompeni Inggris mencari penggantinya, yaitu Daing Mabela. Sejak tahun itulah Daing Mabela menduduki posisi strategis sebagai Kapten Kepala dalam korps militer Bugis (J. Kathirithamby-Wells, 1973:249).

Mengenai proses kedatangan Daing Mabela ke Bengkulu, dilaporkan oleh O.L. Helfrich sebagai berikut:

Omstreeks dien tijd of iets daarvoor had de Engelsche Compagnie zich te Benkoelen gevestigd. Vele binnenlandsche onlusten maakten het haar lastig om handel te drijven. De bewoners van Benkoelen voerden strijd met Soengaj Itam, Soengaj Lemaw had last van voortdurende invallen van redjangers, kortom de toestand was was van dien aard, dat men besloot de hulp in te roepen van een intelligent man, die de partijen gemakkelijk zoude kunnen verzoenen. Het oog viel toen op Daing Mabela, de mede-regeerder van Indrapoera. De grootwaar-digheidbekleeders, de brieven van de Engelsche Compagnie lezende, stemden erin toe, dat Daing Mabela zich naar Benkoelen begaf echter onder voorwaarde, dat hij spoedigst zon terugkeeren. Zoo kwam dan Daing Mabela, vergezeld van vele hoeloebalangs en mantris, te Benkoelen. ${ }^{17}$

Dari isi petikan tersebut di atas, dapatlah dijelaskan, bahwa semenjak berdirinya kompeni Inggris di Bengkulu, pemerintah Inggris mengalami kesulitan dalam melakukan perdagangan, karena sering terjadi penyerbuan yang dilakukan oleh penduduk Sungai Itam yang terdiri atas orang-orang Rejang terhadap penduduk Sungai Lemau. Oleh karena situasi keamanan cukup rawan, maka pemerintah kompeni Inggris memutuskan untuk meminta bantuan kepada Daing Mabela yang saat itu telah menjadi pemimpin pribumi di wilayah Indrapura. Atas kesepakatan para pembesar kerajaan Indrapura, maka berangkatlah Daing Mabela dengan disertai para Hulubalang dan para Mantri menuju Bengkulu.

Sementara itu, sumber naskah Melayu lokal Bengkulu yang berjudul Bahoewa Inilah Asal Oesoel, pada patsal. 31, maupun dalam Tambo Bangkahoeloe, melaporkan sebagai berikut :

Koetika zaman toeankoe Pangeran Mangkoe Radja ialah datang satoe orang dari Indrapoera gelarnja kata orang Indrapoera Soetan Balinam tetapi asal dahoeloe beliauw itoe orang Boegis negri wadjok gelarnja tjara Boegis Daeng Mabela tinggal di Bangkahoeloe beristri mengambil anak tjoetjoeng Datoe 4 di pasjar Bangkahoeloe beranak laki-laki bergelar Daeng Makoeli.

Daeng Makoeli kawin dengan anak Pangeran Mangkoe Radja gelar datoe Njai, Kemoedian ialah Daeng Makoeli itoe diangkat mendjadi Datoe dagang, maka dikoerniai oleh Pangeran pegangan Datoe dagang itoe, dari tanah Merah pendakian dari pantai pasjar Bangkahoeloe laloe dirawang belakang kampoeng Bangkahoeloe sampai dirawang Soeka Marindoe, laloe belah selatan dari djambatan Niboeng, laloe dirawang Goentoeng sampai di tanah Merah, maka Pangeran Mangkoe Radja menjoeroeh merambah dan membersihkan segala hoetan hoetan lingkaran itoe, koetika itoelah mendjadi Padang semoeanja bernamalah Tenga Padang. ${ }^{18}$

Dari isi petikan naskah Melayu tersebut di atas, dapatlah dijelaskan bahwa Daing Mabela datang ke Bengkulu pada zaman Pangeran Mangku Raja memegang kendali pemerintahan pribumi di wilayah Sungai Lemau. Juga diketahui, bahwa nama lain dari daing Mabela 
adalah Sutan Balinam, yang dalam catatan Kathiritahmby-Wells, disebut Sultan Selan.

Menurut sebuah sumber, Daing (Daeng) itu adalag gelar untuk bangsawan menengah, sedangkan Mabela bahasa Bugisnya berarti jauh. ${ }^{19}$ Daing Mabela kemudian menikah dengan anak keturunan dari Datuk Empat Pasar Bangkahulu, dan dari hasil perkawinannya, lahirlah seorang anak laki-laki yang diberi nama Daeng Makulle.

Setelah Daeng Mabella meninggal, jabatan Kapten Bugis, oleh Kompeni Inggris diwariskan kepada anaknya, yaitu Daeng Makulle. Daeng Makulle sendiri selanjutnya menikah dengan Datuk Nyai, putri Pangeran Mangku Raja dari Sungai Lemau di Balai Buntar.

Daeng Makulle juga memperoleh posisi strategis, yaitu mendapat jabatan sebagai Datuk Dagang. Bahkan oleh Pangeran Mangku Raja, telah diberi sebidang tanah untuk mendirikan perkampungan baru (kolonisasi) bagi keluarganya. Sebidang tanah yang masih belukar itu kemudian dibuka, dan akhirnya menjadi sebuah kampung yang diberi nama kampung Tengah Padang.

Menurut laporan Wells, setelah Daeng Makulle kawin dengan anak perempuan Pangeran Sungai Lemau, Daeng Makulle diberi wilayah kekuasaan di Tappa Tuda, yaitu sebuah wilayah yang terbentang dari Pasar Bengkulu hingga perbatasan Utara Selebar. Untuk lebih jelasnya, berikut isi laporannya di bawah ini :

The latter married a doughter of the Pangeran of Sungai Lemau who ceded to him Tappa Tudda, the area stretching from Pasar Benkoelen to the northern border of Silebar. ${ }^{20}$
Melalui kesepakatan antara Pangeran Mangku Raja dari Sungai Lemau dengan Pangeran Djenggalu dari Silebar (Selebar), diangkatlah Daeng Makulle sebagai Penghulu Orang Asing dan keturunannya yang wilayah kekuasaannya mulai dari Ujung Pulau hingga Sungai Lemau. ${ }^{21}$

Pada saat itu, Daeng Makulle juga menerima wewenang dari Kompeni Inggris untuk mengangkat Empat Datuk dari empat Kampung di ibukota Bengkulu dan masing-masing menerima gaji lima real setiap bulannya. Apabila ada sengketa hukum di antara para keturunan Orang Asing, para datuk itu akan mengatasinya masalahnya. Jika belum terselesaikan, maka akan diajukan kepada Daeng Makulle. Akan tetapi jika masih belum beres, maka Daeng Makulle akan mengajukannya kepada Pangeran Sungai Lemau (Pangeran Balai Buntar) atau ke Pemangku. Apabila ternyata masih juga belum tuntas, maka masalah itu akan diajukan oleh Daeng Makulle kepada Kompeni Inggris. ${ }^{22}$

Disamping itu, Daeng Makulle juga menerima sebidang tanah dari Pangeran Sungai Lemau. Tanah tersebut membentang mulai dari Pasar Bangkahoeloe hingga Pasar Sawah, dekat Tanjung Heran. Dari persawahan di belakang Tanjung Agung terus Talang Inci Raja hingga rumah Pajamoran di Pantai. ${ }^{23}$

Sementara dari rumah Pajamoran hingga Krui membentang wilayah kekuasaan Pangeran Jenggalu (Andalas Selebar), sedangkan dari Pasar Bangkahoeloe sampai Sungai Lemau, Pale, Lais, Bintuan, Serangai, Hingga Perbatasan ibukota, adalah wilayah kekuasaan Pangeran Balai Buntar (Sungai Lemau). ${ }^{24}$

Menurut silsilah keluarga bangsawan Bugis di Bengkulu yang ditulis oleh Bakri Ilyas, ${ }^{25}$ dari hasil perkawinan antara Daeng Makulle dengan Datuk Nyai 
(putri Pangeran Mangku Raja dari Sungai Lemau), telah lahir tujuh orang putra. Adapun ketujuh putranya itu, yaitu : Siti Juriyah, Siti Sopia, Siti Sa'diah, Daeng Maruppa, Encik Ismail, Siti Badaria, dan Daeng Marewa. Selanjutnya disebutkan, bahwa Siti Juriyah (Encik Juriya) menikah dengan R. Tumenggung Wirodiningrat dari Madura, Siti Sa'diah menikah dengan R. Sangnata (keponakan R. Tumenggung Wirodiningrat), dan Daeng Maruppa menikah dengan orang Bintuhan (Kaur). ${ }^{26}$ Di antara ketujuh putra Daeng Makulle itu, Daeng maruppa lah yang paling disebut-sebut dalam sumber sejarah, bahkan semua jabatan ayahnya setelah meninggal, diwariskan kepadanya.

Daeng Marupa disebutkan mempunyai anak laki-laki yang diberi nama Si Unus, yang kemudian diberi gelar Daeng Mabella. ${ }^{27}$ Dari silsilah nama-nama keluarga Bugis ini, tampaknya ada dua nama yang dipakai oleh dua keturunan, yaitu Daeng Maruppa dan Daeng Mabella. Nama Daeng Maruppa yang pertama (adik dari Bugis) yang selanjutnya dipakai lagi oleh keturunannya yang ketiga. Sementara nama Daeng Mabella (anak Daeng Maruppa) juga dipakai oleh keturunan ketiga. Menurut catatan Winter, keempat nama Daeng tersebut menjadi sekutu Kompeni Inggris sebagai Kapten Bugis. ${ }^{28}$

Di antara nama-nama keluarga bangsawan Bugis, Daeng Mabella yang kedua lah yang menempati posisi puncak kejayaan keluarga Bugis di Bengkulu di sepanjang sejarahnya hingga tiga dasa warsa di abad ke 19.

Pengaruh kekuasaan Daeng Mabella semakin besar setelah memegang berbagai macam jabatan yang strategis, seperti jabatan Penghulu (kepala) Orang Asing, Kapten Korps Bugis, serta anggota Dewan Pangeran. Akan tetapi setelah dia meninggal (tahun 1832), tidak ada keturunannya yang menggantikan posisinya. ${ }^{29}$

\section{Referensi}

1 Andi Zainal Abidin, Persepsi Orang Bugis, Makassar tentang Hukum, Negara dan Dunia Luar. (Bandung: Alumni, 1983), hlm. 32-33.

2 Mattulada, Kebudayaan Bugis, Makassar (dalam Koentjoroningrat), (Jakarta: Djambatan, 1980), hlm. 262.

3 R.A. Kern, I La Galigo, Bugis Kuno Terjemahan: La Side dan Sagimun, MD. (Yogyakarta: Gadjah Mada University Press, 1993), hlm. 107-114.

${ }^{4}$ Winter, De Familie Daing Mabella, Volgens een Maleisch-handschrift. TNI. 3e Jaargang, 2e deel. (Te Zalt-Bomme bij John Noman en Zoon, 1874), hlm. 116-117.

${ }^{5}$ Andi Zainal Abidin, hlm. 9.

${ }^{6}$ Ibid., hlm. 32-33.

${ }^{7}$ Helfrich, O.L. De Adel van Benkoelen en Djambi (1892-1901). AB. Deel.XXII, Gemengd. 'sGravenhage: Martinus-Nijhoff., 1923. hlm. 317.

${ }^{8}$ Ibid.

9 Ibid., Winter, hlm. 116; J. KathiritahmbyWells, hlm. 247.

${ }^{10}$ O.L. helfrich, hlm. 317.

11 Andi Zainal Abidin, hlm.32-33.

12 P. Wink, , Eenige Archiefstukken Betreffende de Bevestiging van de Engelsche Factorij te Benkoelen in 1685, TBG, LXIV (Batavia: Albrecht \& Co), hlm.464.

${ }^{13} \mathrm{~J}$. Kathirithamby-Wells, A Survey of the Effects of British Influence on Indigenous Authority in Southwest Sumatra (1685-1824), BKI, deel. 129 ('s-Gravenhage: Martinus-Nijhoff, 1973), hlm. 248.

${ }^{14}$ P. Wink, Eenige., hlm. 495.

${ }^{15} \mathrm{~J}$. Kathirithamby-Wells, hlm. 248.

16Rusli Amran, Sumatra Barat Hingga Plakat Panjang.(Jakarta: Sinar Harapan, 1981), hlm.278 ${ }^{17}$ O.L. Helfrich, hlm. 317-318.

${ }^{18}$ Bahoewa Inila Asal-Oesoel, ; H. Delais \& J. Hassan, hlm. 60-61.

19 Shelly Errington, dalam Lorraine Gesick, Pusat Simbol, dan Hirarki Kekuasaan, Esai-Esai tentang Negara-Negara Klasik di Indonesia. Terjemahan: S. Maimoen dan Sonny Keraf. 
(Jakarta: Yayasan Obor Indonesia, 1989), hlm. 1081131.

${ }^{20}$ J. Kathirtithamby-Wells, (1977), hlm. 99.

${ }^{21}$ Winter, hlm. 118.

${ }^{22}$ Ibid.

${ }^{23}$ Ibid. Menurut naskah Melayu, patsal 31, wilayah yang diberikan Mangku Raja kepada Daeng Makulle, meliputi Tanah Merah Pendakian-Pintu Batu-Pasar Bangkahoeloe, terus ke rawang belakang Kampung Bangkahoeloe sampai rawang Sukamerindu. Di sebelah selatan dari Air Jembatan Nibung terus ke rawang Guntung hingga Tanah Merah.

${ }^{24}$ Winter, loc. cit.

${ }^{25}$ Bakri Ilyas, Cerita Raja-Raja Kerajaan Bangkahulu. Penyalin (Bengkulu : Tanpa tahun dan penerbit).

${ }^{26}$ Ibid., hlm. 25.

${ }^{27}$ Winter, hlm. 119.

${ }^{28}$ Ibid.

${ }^{29}$ Ibid., hlm. 120 - 123. Lhat pula: O.L. Helfrich, hlm. 194-197; Nota over Benkoelen Geschreven te Padang, 18 Februarij 1840, door Resident van Ajer Bangies, de Perez (Arsip Nasional, B:6/17). 